\title{
RECYCLING OF COAL ASH AS A BUILDING MATERIAL VIA A STABILIZATION/SOLIDIFICATION METHOD
}

\author{
TINMAZ KÖSE E. \\ AKYILDIZ A. \\ YILDIZ*A.
}

\author{
Çorlu Engineering Faculty \\ Namık Kemal University \\ 59860 Çorlu-Tekirdağ, Turkey
}

Received: 06/02/12

Accepted: 04/10/12 *to whom all correspondence should be addressed: e-mail: ayildiz@nku.edu.tr

\section{ABSTRACT}

This study examines stabilization/solidification (S/S) techniques for coal ash/cement systems that involve the production of construction products while minimizing contamination and recycling the coal ash (CA). In these techniques, the polluted components of coal ash are fixed in a cement body via adsorption and confinement mechanisms, and thus, the possible impact of these pollutants on the environment is minimized. In the first step of this study, the physical, chemical, radioactive and mineralogical properties of the material used were determined. Second, coal ash (CA) was used to replace portland cement $(\mathrm{PC})$ in the following proportions: $0 \%, 5 \%, 10 \%, 15 \%, 20 \%, 25 \%, 30 \%$, $40 \%$ and $50 \%$ of PC by weight. Finally, the usability of coal ash as a construction product and the environmental effects of such usage were determined.

KEYWORDS: Coal ash; Concrete; Recycling; Stabilization/solidification.

\section{INTRODUCTION}

Both the beneficial use of coal ash and the environmental impacts were evaluated. Solidification/stabilization (S/S) methods for coal ash can be used to fix the contaminants within a solidified form.

In the literature, lead, copper, zinc and cadmium have been bound via chemical fixation, and mercury has been encapsulated via physical macroencapsulation, forming insoluble compounds (Conner, 1990; Lagrega et al., 1994). Heavy metals released in the codisposal or codigestion process may affect the performance of the landfill and the anaerobic bioreactors (Uçaroğlu and Talinli, 2002; Bayar and Talinli, 2006; Lo and Liao, 2007; Lo, 2005; Takashima and Speece, 1990; Leighton and Forster, 1998; Alkaln et al., 1996, Lin et al., 1998; Yue et al., 2007; Espinosa et al., 1995). Released heavy metals and other hazardous materials have the potential to cause harm to human health and the environment (Chen and Lin, 2006; Chen and Lin, 2007; Lin and Chen, 2006; Meneses et al., 2004; Watkinson et al., 1998; Lo et al., 2009).

The solidification of wastes with cement and the use of these solidified wastes in the production of construction products has become a common way to minimize environmental contamination and to recycle the wastes. Many researchers are working in this field. In this approach, the waste components are fixed in a cement body via adsorption and confinement mechanisms (Filibeli, 1996); therefore, the possible negative impacts of these wastes on the environment are prevented. In addition, the substitutional use of waste materials in cement provides benefits both in terms of durability and cost-effectiveness.

Huang and Lovell (1990) examined the environmental impacts of waste collection areas and concluded that the base ash may leak into groundwater when stored and thus should be used as a filling material. In one study, the coal ash used for heating homes was bound by lime and cement, which was observed while producing light and porous wall elements. As a result, it was determined that waste ash could be used for the production of building blocks (Demir et al., 2004). Bertolini (2004) and Galiano et al. (2011) studied fly ash; solid waste bottom ash aged 28 days was shown to 
have a compressive strength close to that of the control specimen, which was higher than fly ash. Kurama and Kaya (2008) used the lignite base ash from the Tunçbilek thermal power plant located in Turkey in their study. The specimens were prepared with $5 \%, 10 \%, 15 \%$ and $25 \%$ added ash. The experiments revealed that the most prominent increase in the compressive strength was observed for the sample with $10 \%$ added ash, relative to the standard specimen.

The aim of this study is to determine the usability of coal ash as a construction product and to research the environmental effects of such a usage. For this purpose, eight series of concrete specimens were prepared using Portland cement and a varying amount of ash ( $0 \%$ to $50 \%)$ to study the stabilization of coal ash by solidification.

\section{EXPERIMENTAL}

\subsection{Materials}

\subsubsection{Coal ash (CA)}

Experiments were done using coal ash resulting from the combustion of coal for home heating in the town of Çorlu in the Tekirdağ Province of Turkey. Table 1 shows the physical properties of the coal ash. The chemical compositions, metal content, radioactivity levels and specific surface area of the coal ash were determined using an X-ray fluorescence spectrometer and X-ray diffraction spectroscopy (XRD), conductivity measurements (WTW Cond. 330i Set) and a surface area analysis (Quantachrome Instruments, Nova 400E model), respectively. The major elements analyzed in coal ash are detailed in Table 2 . The heavy metal content and the radioactivity analysis of the coal ash are shown in Tables 3 and 4, respectively.

Table 1. The physical properties of the coal ash

\begin{tabular}{|c|c|c|}
\hline Parameter & & Value \\
\hline Color & & Brown \\
\hline Density & $\mathrm{kg} \mathrm{m}^{-3}$ & 1913.51 \\
\hline Pore volume & $\mathrm{cc} \mathrm{g}^{-1}$ & 0.021 \\
\hline Specific surface area & $m^{2} g^{-1}$ & 14.067 \\
\hline Electrical conductivity & $d S m^{-1}$ & 8.80 \\
\hline $\mathrm{pH}$ & & 9.40 \\
\hline
\end{tabular}

Table 2. Chemical compositions of the coal ash (Data obtained from the XRD analysis)

\begin{tabular}{lcccccccccc}
\hline Oxide & $\mathrm{SiO}_{2}$ & $\mathrm{Al}_{2} \mathrm{O}_{3}$ & $\mathrm{Fe}_{2} \mathrm{O}_{3}$ & $\mathrm{CaO}$ & $\mathrm{MgO}$ & $\mathrm{SO}_{3}$ & $\mathrm{Na}_{2} \mathrm{O}$ & $\mathrm{K}_{2} \mathrm{O}$ & $\mathrm{TiO}_{2}$ & $\mathrm{P}_{2} \mathrm{O}_{5}$ \\
\hline $\begin{array}{l}\text { Coal ash } \\
\text { (wt.\%) }\end{array}$ & 41.369 & 17.937 & 9.988 & 9.264 & 8.333 & 9.695 & 0.575 & 1.387 & 0.825 & 0.211 \\
\hline
\end{tabular}

Table 3. Metal content in the coal ash

\begin{tabular}{lcccccc}
\hline \multicolumn{1}{c}{ Element } & $\mathrm{As}$ & $\mathrm{Zn}$ & $\mathrm{Cr}$ & $\mathrm{Ni}$ & $\mathrm{Cu}$ & $\mathrm{Ba}$ \\
\hline $\begin{array}{l}\text { Coal ash } \\
\text { (wt.\%) }\end{array}$ & 0.004 & $\begin{array}{c}0 . \\
010\end{array}$ & 0.021 & 0.018 & 0.011 & 0.056 \\
\hline
\end{tabular}

Table 4. Radioactivity analysis of the coal ash

\begin{tabular}{lccccc}
\hline Element & Cs-134 & Cs-137 & K-40 & Ra-226 & Th-232 \\
\hline $\begin{array}{l}\text { Coal ash } \\
\text { Bq kg }\end{array}$ & $<3,6$ & $<4,2$ & $272.2 \pm 30.7$ & $86.1 \pm 4.9$ & $48.3 \pm 4.7$ \\
\hline
\end{tabular}

The mineralogical analysis of the ash specimen was carried out using a $\mathrm{Cu}$ X-Ray tube (1.5405 Angstroms), and quartz, hematite, calcite, feldspar and magnesioferrite were observed in the compound. The XRD pattern is given in Figure 1, SEM micrograph of the coal ash is given Figure 2 and a plot of the surface area of the coal ash is given in Figure 3. 


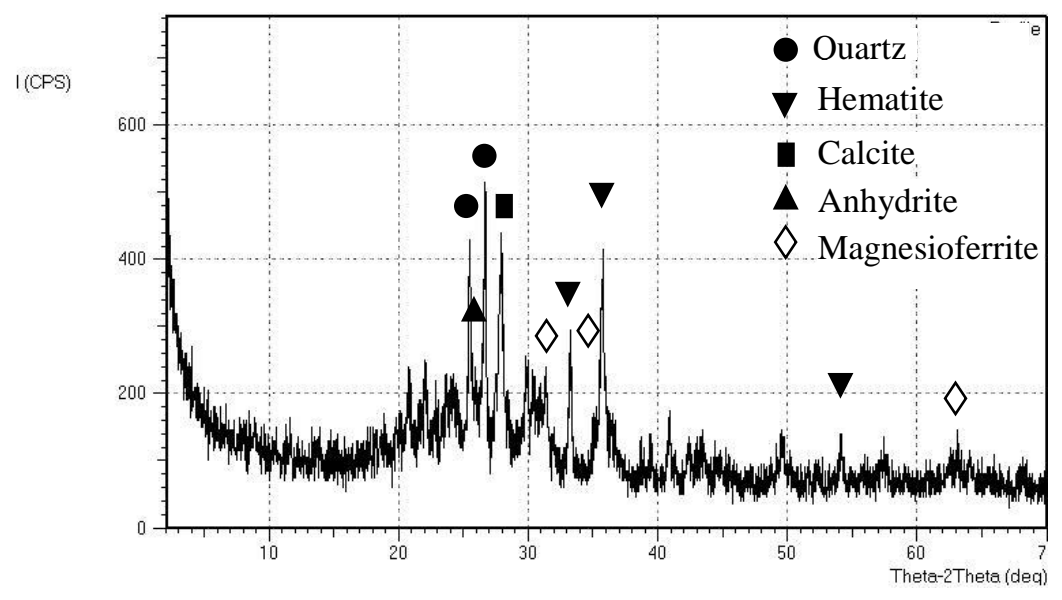

Figure 1. XRD pattern of the coal ash
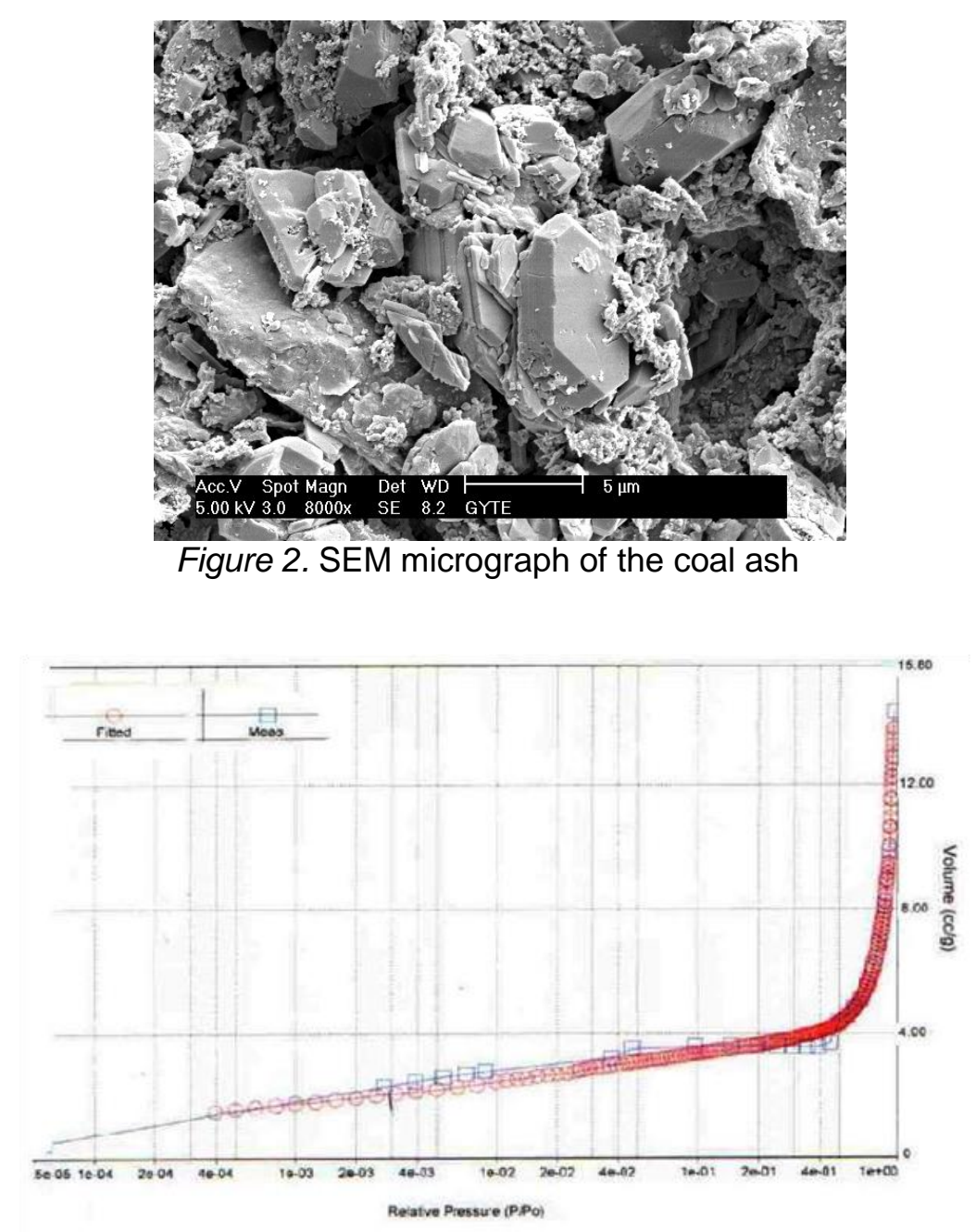

Figure 3. Surface area of the coal ash 


\subsubsection{Characterization of the other materials}

Cement (CEM I 42.5 R) was supplied from Akçansa, in Turkey. It complied with the requirement of European Standards EN 197-1. The physical, chemical and mechanical properties of the cement are given in Table 5.

Table 5. The physical, chemical and mechanical properties of cement

\begin{tabular}{llll}
\hline & \multicolumn{1}{c}{ PROPERTIES } & UNIT & Cement \\
\cline { 2 - 4 } CHEMICAL & Insoluble Residue & $\%$ & 0.5200 \\
PROPERTIES & $\mathrm{SO}_{3}$ & $\%$ & 3.1100 \\
& Loss on Ignition & $\%$ & 1.25 \\
& $\mathrm{Cl}$ & $\%$ & 0.0385 \\
\hline & Specific Gravity & $\mathrm{g} \mathrm{cm}^{-3}$ & 3.14 \\
& Initial setting time & $\mathrm{min}$ & 137 \\
PHYSICAL & Final setting time & $\mathrm{min}$ & 194 \\
PROPERTIES & Volume expansion & $\mathrm{mm}^{-}$ & 1 \\
& Specific Surface Area & $\mathrm{cm}^{2} \mathrm{~g}^{-1}$ & 3700 \\
& Fineness 45 $\mu \mathrm{m}$ & $\%$ & 8.6 \\
& Fineness 90 $\mu \mathrm{m}$ & $\%$ & 0.3 \\
\hline MECHANICAL & Compressive Strength, 2 days & $\mathrm{MPa}$ & 26.6 \\
PROPERTIES & Compressive Strength, 7 days & $\mathrm{MPa}$ & 40.8 \\
& Compressive strength, 28 days & $\mathrm{MPa}$ & 55.8 \\
\hline
\end{tabular}

A maximum $22 \mathrm{~mm}$ nominal size of the crushed aggregate was used. The coarse aggregates were calcareous stone: crushed stone I (6-12 mm), crushed stone II (12-22 mm), natural sand (0-3 mm) and crushed dusty stone dusty $(0-6 \mathrm{~mm})$. The granulometric curves and the mixture size distribution are provided in Figure 4. The specific gravities of the raw materials are listed in Table 6.

Table 6. Specific gravity of the raw materials

\begin{tabular}{lccccc}
\hline Material & $\begin{array}{c}\text { Portland } \\
\text { cement }\end{array}$ & $\begin{array}{c}\text { Crushed } \\
\text { stone I }\end{array}$ & $\begin{array}{c}\text { Crushed } \\
\text { stone II }\end{array}$ & $\begin{array}{c}\text { Natural } \\
\text { sand }\end{array}$ & $\begin{array}{c}\text { Crushed } \\
\text { dusty } \\
\text { stone }\end{array}$ \\
\hline $\begin{array}{l}\text { Coal ash } \\
\mathrm{kg} \mathrm{m}^{-3}\end{array}$ & 3.14 & 2.564 & 2.564 & 2.630 & 2.500 \\
\hline
\end{tabular}

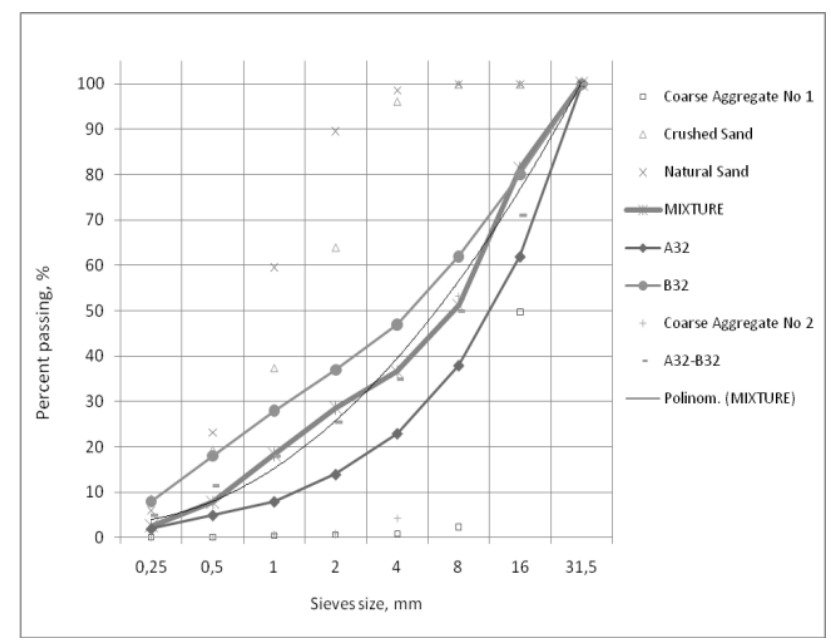

Figure 4. Granulometric curves for the aggregates and mixtures 


\subsection{Experiment Methods}

\subsubsection{Solidification method}

The amount of cement used in the mixtures was $300 \mathrm{~kg} \mathrm{~m}^{-3}$. The volume of the aggregate was used to determine the aggregate weight. Coal ash was used to replace PC at $0 \%, 5 \%, 10 \%, 15 \%, 20 \%$, $25 \%, 30 \%, 40 \%$ and $50 \%$ by weight. Aggregate dry mixing was applied for approximately 30 seconds. Next, cement and coal ash were added at different rates, dry mixing was applied for another 30 seconds, water was added to the mixture and the mixture was mixed for 1.5 minutes. After this period, the mixer was stopped, and the mixture was left to rest for one minute. A slump test was performed on every concrete sample produced, and the slump value was set to approximately $7-8 \mathrm{~cm}$ in all of the mixtures. The mixtures were cast into cubic molds $(150 \mathrm{~mm} \times 150 \mathrm{~mm} \times 150$ $\mathrm{mm}$ ). The molds were then filled with concrete in three layers. Each layer was compacted using a vibrating table for $10 \mathrm{~s}$ and then stored in molds at room temperature for $24 \mathrm{~h}$. After that, the specimens were removed from the molds. The specimens were cured in air at room temperature $(\approx$ $23-25^{\circ} \mathrm{C}$ and relative humidity $\approx 75 \%-85 \%$ ) for 7 and 28 days. After 7 and 28 days of curing, the samples were crushed and sieved to $9 \mathrm{~mm}$ and were extracted using leaching tests.

\subsubsection{Compressive strength test}

The compressive strength of the cubic specimens $(150 \times 150 \times 150 \mathrm{~mm})$ was measured according to TS EN 12390-3 (2002) at the ages of 7 and 28 days. Three specimens were tested for each mixture at each age, and the mean values were reported.

\subsubsection{Leaching test}

The stabilization/solidification efficacy was assessed from a chemical point of view according to the leaching (U.S. EPA TCLP) test. The U.S. EPA TCLP (toxicity characteristic leaching procedure) (US EPA, 1986) method no. 1311 test consists of stirring the granular material $(<9 \mathrm{~mm})$ with an acetic acid solution at $\mathrm{pH} 4.93 \pm 0.05$ (fluid no. 2) with a liquid/solid ratio (L/S) of 20 for $18 \mathrm{~h}$. After the test, samples were filtered through Whatman membrane filters (pore size $0.45 \mu \mathrm{m}$ ). When the procedures were completed, the metal contents in the solutions were determined using inductively coupled plasma techniques.

\subsubsection{Water microorganism growth test}

To study the effects of the produced concrete on water quality, a "water microorganism growth test" was done in accordance with BS 6920 (1996). For these measurements, the solidified material was left for 21 days in water whose dissolved oxygen content had been premeasured. According to the method, the difference in the amount of dissolved oxygen at the beginning and the end of the experiment was less than $2.4 \mathrm{mg} / \mathrm{l}$, which means that no microbiologic reproduction had occurred in the medium.

\section{RESULTS AND DISCUSSION}

\subsection{Compressive strength}

Three specimens of solidified/stabilized cement and a pure cement sample (blank sample) (Table 4) were subjected to compressive strength testing after curing using a compression machine. The ends of the specimens were ground flat and parallel before testing, and the results reported are the average of three specimens. Among the concrete samples in which coal ash was used in place of cement $5 \%, 10 \%, 15 \%, 20 \%, 25 \%, 30 \%, 40 \%$ and 50\% (for which 7 -day cure samples were obtained) the group that yielded the value closest to the blank sample was the $10 \%$ ash group. For the 28-day cure samples, the closest value to the blank sample was obtained from the $5 \%$ mixture. As seen in Figure 3, according to the 28-day cure results, the concrete samples that were produced with mixtures of up to $20 \%$ ash satisfy the $30 \mathrm{MPa}$ strength requirement prescribed for C25 class concrete. The 7 and 28 days strength values and their differentiation rates are given in Table 7 and the compressive strength of the 7 and 28 days cure specimens is given in Figure 5. 
Table 7. The 7 and 28 days compressive strength values of coal ash and the percent change

\begin{tabular}{ccccc}
\hline Coal ash & \multicolumn{2}{c}{$\begin{array}{c}\text { Compressive Strength } \\
(\mathrm{MPa})\end{array}$} & \multicolumn{2}{c}{ Percent Change } \\
\hline$\%$ & 7 days & 28 days & 7 days & 28 days \\
\hline 0 & 32.12 & 37.98 & 100 & 100 \\
\hline 5 & 32.30 & 36.94 & 101 & 97 \\
\hline 10 & 32.50 & 31.91 & 101 & 84 \\
\hline 15 & 27.05 & 31.19 & 84 & 82 \\
\hline 20 & 27.86 & 33.39 & 87 & 88 \\
\hline 25 & 19.77 & 27.95 & 62 & 74 \\
\hline 30 & 20.41 & 29.54 & 64 & 78 \\
\hline 40 & 15.45 & 28.62 & 48 & 75 \\
\hline 50 & 10.39 & 20.26 & 32 & 53 \\
\hline
\end{tabular}

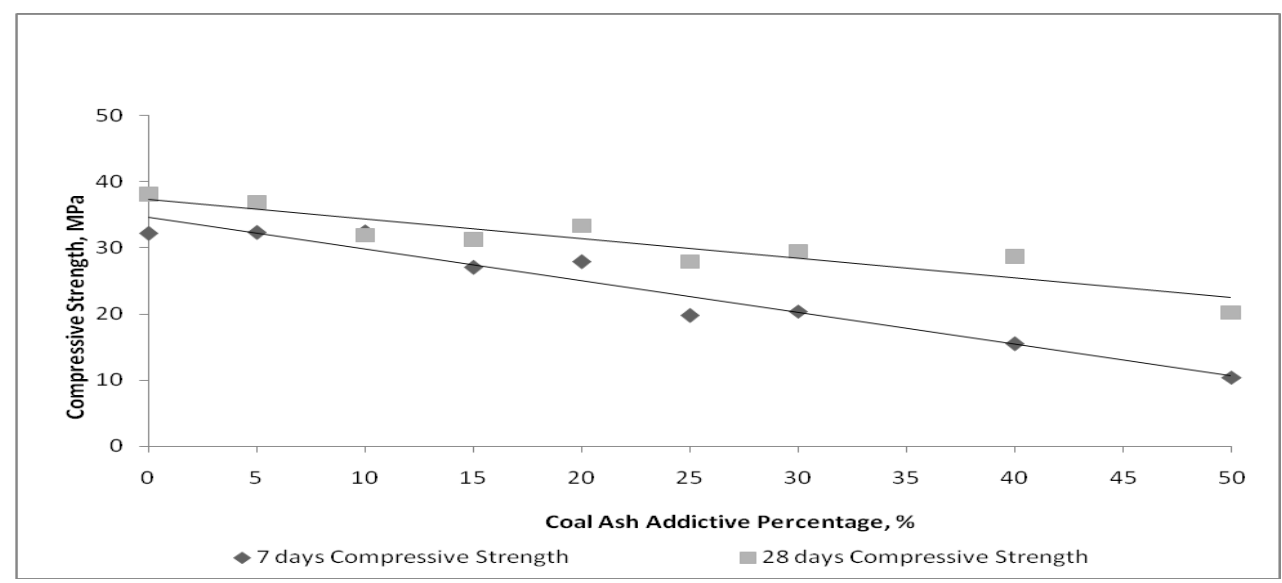

Figure 5. The compressive strength of the 7 and 28 days cure specimens

As seen in Table 4 and Figure 5, the inclusion of coal ash reduced the strength of the concrete specimens. The loss of strength varied in a nearly linear manner as the percentage of ash increased. When the curing time is taken into account, it can be observed that the strength increased with time. Notably, concrete specimens with compressive strength levels near $30 \mathrm{MPa}$ could be prepared; this characteristic indicates that concrete specimens produced with coal ash replacing cement in amounts of up to $20 \%$ could be used as building materials.

\subsection{Leaching test}

Table 8 shows the results obtained from the leaching test. It can be seen that the values of the heavy metals measured for the concrete specimens were similar to those obtained from the ash samples themselves and to the blank concrete samples for each replacement percentage. Generally, as the percentage of cement replaced by coal ashes in the concrete increased, the leachability of heavy metals also increased. Nevertheless, the values of the leachability of the concrete specimens were similar for all replacement percentages at both curing times. As seen in Figure 4, according to the 28-day cure results, the concrete samples that were produced with mixtures of up to $20 \%$ ash satisfied the $30 \mathrm{MPa}$ strength requirement prescribed for C25 class concrete. This replacement percentage is also the proper percentage to use according to the heavy metal values.

It can also be seen that the values of $\mathrm{Ca}, \mathrm{K}, \mathrm{Na}, \mathrm{Al}, \mathrm{Fe}$ and $\mathrm{Si}$ measured in the concrete specimens were similar to the values in the corresponding ash samples. 
Table 8. Metal concentrations in the US EPA TCLP (1311) leachate at 7 and 28 days

\begin{tabular}{|c|c|c|c|c|c|c|c|c|c|c|}
\hline & & \multicolumn{9}{|c|}{$\operatorname{TCLP}\left(\mathrm{mg} \mathrm{l}^{-1}\right)$} \\
\hline & & Cd & $\mathrm{Cr}$ & $\mathrm{Cu}$ & $\mathrm{Ni}$ & $\mathrm{Zn}$ & $\mathrm{Al}$ & $\mathrm{Fe}$ & Mg & Si \\
\hline COAL & H (CA) & $<0.06$ & 3.3361 & $<0.6$ & 3.3595 & 3.5335 & 390.782 & 61.5923 & 1210.44 & 1234.67 \\
\hline \multirow{2}{*}{ CAO } & 7 & $<0.06$ & 0.2273 & $<0.6$ & $<0.02$ & 3.2589 & 5.8609 & 4.5121 & 148.256 & 185.248 \\
\hline & 28 & $<0.06$ & 0.4706 & $<0.6$ & $<0.02$ & 2.9582 & 16.2493 & 3.6852 & 146.300 & 46.0539 \\
\hline \multirow{2}{*}{ CA5 } & 7 & $<0.06$ & 0.9674 & $<0.6$ & $<0.02$ & $<0.6$ & 6.6568 & 3.1336 & 32.2558 & 161.847 \\
\hline & 28 & $<0.06$ & 0.3850 & $<0.6$ & $<0.02$ & $<0.6$ & 1.4592 & 1.5682 & 22.8852 & 365.448 \\
\hline \multirow{2}{*}{ CA10 } & 7 & $<0.06$ & 0.5098 & $<0.6$ & $<0.02$ & $<0.6$ & 1.8771 & 1.7540 & 45.8310 & 485.239 \\
\hline & 28 & $<0.06$ & 0.4055 & $<0.6$ & $<0.02$ & $<0.6$ & 1.8108 & 1.3770 & 35.0735 & 485.897 \\
\hline \multirow{2}{*}{ CA15 } & 7 & $<0.06$ & 0.5383 & $<0.6$ & $<0.02$ & $<0.6$ & 2.1894 & 1.5963 & 138.536 & 643.805 \\
\hline & 28 & $<0.06$ & 0.3564 & $<0.6$ & $<0.02$ & $<0.6$ & 1.3835 & 1.8712 & 56.8751 & 512.243 \\
\hline \multirow{2}{*}{ CA2O } & 7 & $<0.06$ & 0.3215 & $<0.6$ & $<0.02$ & $<0.6$ & 7.2369 & 1.4302 & 25.5879 & 117.205 \\
\hline & 28 & $<0.06$ & 0.3219 & $<0.6$ & $<0.02$ & 3.7916 & 48.7921 & 57.3125 & 116.932 & 173.527 \\
\hline \multirow{2}{*}{ CA25 } & 7 & $<0.06$ & 0.4473 & $<0.6$ & $<0.02$ & $<0.6$ & 6.1867 & 1.3367 & 58.6985 & 111.327 \\
\hline & 28 & $<0.06$ & 0.4002 & $<0.6$ & $<0.02$ & 1.0731 & 38.6962 & 54.3095 & 250.888 & 223.277 \\
\hline \multirow{2}{*}{ CA30 } & 7 & 06 & 0.4840 & $<0.6$ & $<0.02$ & $<0.6$ & 4.5873 & 2.0085 & 36.5289 & 265.970 \\
\hline & 28 & $<0.06$ & 0.3791 & $<0.6$ & & $<0$ & 102.408 & 21.2594 & 292.372 & 494.947 \\
\hline \multirow{2}{*}{ CA40 } & 7 & $<0.06$ & 0.3809 & $<0.6$ & $<0.02$ & $<0.6$ & 59.0817 & 12.6393 & 224.091 & 281.971 \\
\hline & 28 & $<0.06$ & 0.5329 & $<0.6$ & $<0.02$ & $<0.6$ & 141.056 & 25.3538 & 399.712 & 758.309 \\
\hline \multirow{2}{*}{ CA50 } & 7 & $<0.06$ & 0.7500 & $<0.6$ & $<0.02$ & $<0$ & 17.1955 & 31.0240 & 1076.84 & 216.464 \\
\hline & 28 & $<0.06$ & 0.0963 & $<0.6$ & $<0.02$ & 1.1112 & 137.207 & 23.6030 & 572.184 & 708.422 \\
\hline
\end{tabular}

\subsection{Water microorganism growth test}

The test (according to British Standards BS 6920) assesses the ability of a product to promote a significant degree of growth of aerobic microorganisms when they come into contact with water. This test takes 8 weeks to complete. As seen in Table 9, the difference in the amount of dissolved oxygen at the beginning and the end of the experiment was less than $2.4 \mathrm{mg} / \mathrm{l}$ (Table 10) for all percentages on both curing days. These results indicate that no microbiologic reproduction occurs in the medium for any of the percentages. The results indicate that the aforementioned mixtures containing coal ash as an additive material did not experience any issues associated with microorganism reproduction.

Table 9. Dissolved oxygen values in water samples

\begin{tabular}{|c|c|c|c|c|}
\hline Sample & $\begin{array}{l}\text { Dissolved } \mathrm{O}_{2} \\
\left(\text { start, } \mathrm{mg} \mathrm{l}^{-1}\right)\end{array}$ & $\begin{array}{c}\text { Dissolved } \mathrm{O}_{2} \\
\left.\text { (end, } \mathrm{mg} \mathrm{l}^{-1}\right)\end{array}$ & $\begin{array}{c}\text { Difference } \\
\left(\mathrm{mg} \mathrm{l}^{-1}\right)\end{array}$ & Action \\
\hline CA 5 & 7.4 & 6.2 & 1.2 & Pass \\
\hline CA 10 & 7.4 & 6.9 & 0.5 & Pass \\
\hline CA 15 & 7.4 & 6.7 & 0.7 & Pass \\
\hline CA 20 & 7.4 & 6.9 & 0.5 & Pass \\
\hline CA 25 & 7.4 & 6.5 & 0.9 & Pass \\
\hline CA 30 & 7.4 & 6.3 & 1.1 & Pass \\
\hline CA 40 & 7.4 & 6.2 & 1.2 & Pass \\
\hline CA 50 & 7.4 & 6.9 & 0.5 & Pass \\
\hline
\end{tabular}

Table 10. Growth of aquatic microorganisms test requirements (BS 6920)

\begin{tabular}{ccc}
\hline Result $\left(\mathrm{mg} \mathrm{l}^{-1}\right)$ & $<2.4$ & $\geq 2.4$ \\
\hline Action & Pass & Fail \\
\hline
\end{tabular}




\section{CONCLUSIONS}

The results of this study that investigated the recycling of coal ash via solidification/stabilization methods can be summarized as follows:

- Increasing the percentage of coal ash linearly reduced the strength of the concrete specimens because of the high organic content of the coal ash.

- The strength increased with curing time.

- Concrete specimens produced with coal ash replacing up to $20 \%$ of the cement had compressive strength levels near the $30 \mathrm{MPa}$ value prescribed for C25-class concrete.

- The leaching concentrations of metals in the manufactured concrete samples were compared with the ash samples themselves, and it was concluded that the solidification/stabilization process was a successful method for recycling coal ash.

- The concrete samples that were produced with mixtures of up to $20 \%$ ash satisfied the 30 $\mathrm{MPa}$ strength requirements, and this replacement percentage is the proper percentage to use, according to the heavy metal leaching results. The analysis carried out to determine the effects of the produced concrete samples on the water microorganisms revealed that the difference between the starting and ending concentrations of dissolved oxygen was $2.4 \mathrm{mg} / \mathrm{l}$; therefore, there was no organic material dissolution and thus no reproduction of microorganisms.

- Taking into consideration the strength tests and the leaching and water microorganism growth experiments, it was concluded that coal ash is suitable as an additive construction product when it is used to replace cement in proportions up to $20 \%$. Coal ash used in this way has no hazardous impacts on the environment.

\section{ACKNOWLEDGMENTS}

This paper was developed under the support of the project TUBITAK, 108Y233: "The investigation of the use of building materials with the aim of disposing of different ash and mud samples".

\section{REFERENCES}

Alkaln U., Anderson G.K. and Ince O., (1996), Toxicity of trivalent chromium in the anaerobic digestion process, Water Res., 3, 731-741.

Bayar S. and Talinli I., (2006), Management of hazardous wastes by solidification/stabilization technology, iTÜ/d Journal, 5, 281-289.

Bertolini L., (2004), MSWI ashes as mineral additions in concrete. Cement and Concrete, 348, 18991906.

British Standards-(BS 6920), (1996), Designed for Human Consumption of Water Quality Effects of metals used in contact with water, taking into account the non-availability.

Chen B.Y. and Lin K.L., (2006), Biotoxicity assessment on reusability of municipal solid waste incinerator (MSWI) ash, J. Hazard. Mater, B136, 741-746.

Chen B.Y. and Lin K.L., (2007), Dose-mortality assessment on municipal solid waste incinerator (MSWI) ash, J. Hazard. Mater, A139, 19-24.

Conner J.R, (1990), Chemical Fixation and Solidification of Hazardous Wastes. Van Nostrand Reinhold. ISBN 0-442-20511-2, 682 .

Demir İ., Başpınar S., Kıbıcı Y. and Yıldız A., (2004), Investigated using the whole building block heaters to produce, Symposium on industrial raw materials, 5, 97-100.

Espinosa A., Rosas L., llangovan K. and Noyola A., (1995), Effect of trace metals on the anaerobic degradation of volatile fatty acids in molasses stillage, Water Res., 32, 121-129.

Filibeli A., (1996), Sewage Sludge Processing. Dokuz Eylül University, Engineering Faculty. 255, İzmir

Galiano L.Y., Pereira F.C. and Vale J., (2011), Stabilization/solidification of a municipal solid waste incineration residue using fly ash-based geopolymers, Journal of Hazardous Materials, 185, 373-381.

Huang W.H. and Lovell C.W., (1990), Bottom ash as an embankment material. In: Arvid, Landva, David Knowles, G. eds., Geotechnics of waste fills - theory and practice, ASTM STP 1070. American Society for Testing and Materials, Philadelphia,

Kurama H. and Kaya M., (2008), Usage of coal combustion bottom ash in concrete mixture, Construction and building materials, 22, 1922-1928. 
Lagrega M.D., Buchingam P.L. and Evans J.C., (1994), Hazardous Waste Management. Mc Graw Hill Inc. 1103 p.

Leighton I.R. and Forster C.F., (1998), The effect of heavy metals on a thermophilic methanogenic upflow sludge blanket reactor, Bioresour. Technol, 63, 131-137.

Lin C.Y., Chou J. and Lee Y.S., (1998), Heavy metal-affected degradation of butyric acid in anaerobic digestion. Bioresour. Technol., 65, 159-161.

Lin K.L. and Chen B.Y., (2006), Understanding biotoxicity for reusability of municipal solid waste incinerator (MSWI) ash, Journal of Hazardous Material, B138, 9-15.

Lo H.M. and Liao Y.L., (2007), The metals-leaching and acids-neutralizing capacity of MSW incinerator ash co-disposed with MSW in landfill sites, Journal Hazardous Materials, 142, 412-519.

Lo H.M., (2005), Metals behaviors of MSWI bottom ash co-digested anaerobically with MSW. Resourse Conservation Recycle, 43, 263-280.

Lo H.M., Lin K.C., Liu, M.H., Pai T.Z., Lin C.Y., Liu W.F., Fang G.C., Lu C., Chiang C.F., Wang S.C., Chen P.H., Chen J.K., Chiu H.Y and Wu K.C. (2009), Solubility of heavy metals added to MSW, Journal of Hazardous Materials. 161, 294-299.

Meneses M., Schuhmacher M. and Domingo J., (2004), Health risk assessment of emission of dioxins and furans from a municipal waste incinerator: comparison with other emission sources, Environment Int, 30, 481-489.

Takashima M. and Speece R.E., (1990), Mineral requirements for methane fermentation. Crit. Rev. Environment Control, 19, 465-479.

TS EN 197-1, (2002), Cement-Part 1: Compositions and Conformity Criteria for Common Cements, Turkish Standard Institute, Ankara, Turkey

US EPA, (1986), Test methods for evaluating solid wastes, toxicity characteristic leaching procedure (TCLP), Method 1311 SW-846, third ed., Environmental Protection Agency, Washington, DC, USA,

Uçaroğlu S. and Talınlı I.,, (2002), Hazardous Waste of the automotive industry, Solidification and Recycling, ITÜ/d Journal, 1, 39-50.

Watkinson W.P., Campen M.J. and Costa D.L., (1998), Cardiac arrhythmia induction after exposure to residual oil fly ash particles in a rodent model of pulmonary hypertension, Toxicological Science, 41, 209-216.

Yue Z.B., Yu H.Q. and Wang Z.L. (2007), Anaerobic digestion of cattail with rumen culture in the presence of heavy metals, Bioresour Technology, 98, 781-786. 